TRANS · NÚM. I2 $\cdot 2008$

DOSSIER · 43-50
Andrés Bello y Gertrudis Gómez de Avellaneda tradujeron, cada uno por su parte y desconociendo seguramente la respectiva versión del otro/de la otra, el poema de Victor Hugo "Les Djinns» a comienzos de los años cuarenta del siglo XIX. Este artículo analiza las estrategias de traducción utilizadas por Avellaneda y por Bello y estudia la funcionalización de cada una de las traducciones en el contexto cultural especifico tomando en cuenta el lugar de enunciación respectivo. Punto de partida del análisis es la tesis de que dicho lugar está significativamente marcado por la diferencia de género/gender en el caso de Avellaneda, y por la localización geocultural en el caso de Bello.

Palabras Clave: Gertrudis Gómez de Avellaneda, Andrés Bello, Victor Hugo, lugar de traducción, orientalismo.

\title{
¿Orientalismos americanos? Lugares de traducción de Gertrudis Gómez de Avellaneda y de Andrés Bello*
}

In the 1840s both Andrés Bello and Gertrudis Gómez de Avellaneda translated - probably ignoring each other's translation - the famous poem of Victor Hugo "Les Djinns". This article analyzes the translation strategies used by Avellaneda and Bello, paying attention to the translation's function in each cultural context and to the locus of enunciation of each translator. The thesis is that the locus of enunciation of Avellaneda as translator of Victor Hugo is to a significant degree determined by gender difference, and that of Bello by geocultural location.

Andrea Pagni

Universidad Erlangen-Nuremberg, Alemania

KEYWORDS: Gertrudis Gómez de Avellaneda; Andrés Bello, Victor Hugo, locus of translation, orientalism. 


\section{INTRODUCCIÓN}

El poema de Víctor Hugo «Les Djinns», publi44 cado en Les Orientales en I828, fue objeto de numerosas traducciones debido sobre todo a su peculiar formato, que invita a la experimentación: en quince estrofas de ocho versos cada una, Víctor Hugo utilizó respectivamente metros en orden creciente hasta la octava estrofa y decreciente hasta la décimoquinta, manteniendo en todas las estrofas el mismo esquema de rima. El crescendo y decrescendo métrico se corresponde en el plano semántico con el acercamiento, la presencia amenazadora y el alejamiento de los djinns, espíritus aéreos malignos del imaginario oriental convocado por Hugo, que comienzan a obsesionar al yo lírico en la noche, culminando su asedio en la estrofa central del poema, compuesta en versos alejandrinos, y se alejan hacia el final hasta desaparecer.

Esta composición atrajo hacia I840 la atención de Gertrudis Gómez de Avellaneda y de Andrés Bello, quienes publicaron sendas «imitaciones» de Víctor Hugo con el título de «Los duendes». La escritora cubana incluyó el poema en sus Poesías (Madrid I84I), reeditándolo con algunas variantes en I850 y con importantes cambios en sus Obras Completas aparecidas en varios volúmenes a partir de I869, también en Madrid. Andrés Bello, por su parte, publicó su versión en el periódico chileno El Progreso de Santiago de Chile en I843, dos meses antes de pronunciar su discurso inaugural como rector de la recién fundada Universidad de Chile, discurso en el que retoma aspectos importantes

Una versión previa de este trabajo fue presentada en las Primeras Jornadas Hispanoamericanas de Traducción Literaria en Rosario (Argentina), 22 al 25 de noviembre de 2006. de la polémica sobre el romanticismo y sobre Víctor Hugo, que había tenido lugar en Chile un año antes.

Seguramente Andrés Bello y Gertrudis Gómez de Avellaneda desconocieron la coincidencia de sus traducciones; lo que importa es, sin embargo, que ambos se sintieron atraídos no sólo por Víctor Hugo, sino también justamente por ese poema, y que sus versiones difieren notablemente entre sí.

Analizaré a continuación determinadas estrategias de traducción utilizadas por Avellaneda y Bello tomando en cuenta el respectivo lugar de enunciación o más precisamente: el lugar de traducción, locus traductionis, que asumen. Punto de partida del análisis es la tesis de que ese lugar está significativamente marcado por la diferencia de género/gender en el caso de Avellaneda, y por la localización geocultural en el caso de Bello.

\section{LUGARES DE ENUNCIACIÓN}

Publicado en 1828, Les Orientales es producto de la fascinación orientalista europea de comienzos del siglo xix. Inspirándose en el Goethe del Divan, en Byron, en los hermanos Schlegel y Chateaubriand, Víctor Hugo plasmó en este libro de poemas las emociones exóticas y las asociaciones plásticas y visuales que poblaban el imaginario francés de los años veinte del siglo XIX, modelado por la campaña napoléonica en Egipto, todavía reciente, por el surgimiento de la arqueología, a partir de los hallazgos de esa misma expedición, por la pintura de Delacroix y por la guerra de Grecia. En el prefacio a Les Orientales Hugo sostiene que así como el siglo de Luis xiv había sido el del helenismo, el siglo XIX era el del orientalismo, un término recientemente acuñado, y que Hugo postula como programa. La localización geocultural 
de ese orientalismo era el ámbito mediterráneo extraeuropeo que, desde la perspectiva francesa, incluía el norte de África, Egipto, y también a España. Los poemas vinculan el exotismo orientalista con el tomar partido por la lucha libertaria en Grecia, en la que participó Byron, con quien Víctor Hugo simpatizaba abiertamente. Sin embargo, más allá de los datos políticos, es un Oriente intemporal, un topos, el que se pone de manifiesto en estos poemas de Víctor Hugo, cuya influencia en la poesía europea moderna puede rastrearse en Baudelaire, en Rimbaud, en Verlaine, en los simbolistas, y en los poetas de fin de siglo.

No fue sin embargo esta dimensión orientalista, explícita en «Les Djinns» desde su título, la que atrajo la atención de Gertrudis Gómez de Avellaneda y de Andrés Bello. En las respectivas culturas de llegada el orientalismo no tenía la importancia que tenía en Francia. Los contextos culturales de Avellaneda en la España de I840 y los de Bello en el Chile de I843 son otros. Así, ambas versiones elaboran representaciones domésticas de «Les Djinns» $y$ de la cultura en que fue escrito, y construyen también respectivamente una posición de inteligibilidad (Venuti, I998: 68) que es también una posición ideológica, vinculada a los códigos y cánones, intereses y agendas de determinados grupos sociales en la cultura de llegada. Publicado inicialmente en la edición de las Poesias de la escritora cubana, «Los duendes» no remite en primer término al imaginario orientalista convocado en Les Orientales, sino al contexto/ cotexto de la obra poética de Avellaneda y a la problemática que esa obra articula. Bello por su parte publica «Los duendes» en El Progreso de Santiago de Chile en julio de I843, poco después de que tuviera lugar allí la polémica literaria sobre el romanticismo en general y sobre Víctor Hugo en particular, en la que Bello había participado de manera indirecta (Pagni, 2004).

Si no fue el tema orientalista, ¿qué fue, exactamente, lo que atrajo la atención de Avellaneda y Bello? Posiblemente el experimento formal 45 de «Les Djinns». Una vez sugerida esta hipótesis, puede parecer paradójico dejar de lado, como propongo ahora, justamente la dimensión métrica y sintáctica, y poner el acento en aspectos pragmático-semánticos, desatendiendo justamente lo que debió ser - para sus respectivos autores- el punto de partida de las dos imitaciones. Sólo señalaré que Andrés Bello mantuvo hasta cierto punto en «Los duendes» el esquema métrico ascendente-descendente, y que Gertrudis Gómez de Avellaneda utilizó en su versión ritmos polimétricos sin atenerse al esquema de «Les djinns», mientras que en un poema estrechamente vinculado con «Los duendes», titulado "La noche de insomnio y el alba. Fantasía», Avellaneda empleó el esquema métrico ascendente, comenzando con bisílabos y terminando con el verso de i6 sílabas en estrofas de ocho versos consonantados.

\section{PRAGMÁTICA DE «LES DJINNS»}

Una de las características que la crítica ha destacado en Les Orientales, es que en esta colección de poemas aparece un yo lírico variable, que ocupa diversas posiciones y asume identidades distintas. Les Orientales está construido sobre el modelo de un texto dramático que delega la palabra a diversos personajes (Charles-Wurtz, 1998: 470). El hablante lírico es entonces a la vez subjetivo e impersonal; esa posición aparece ocupada por voces y roles diferentes. La identidad entre el yo lírico y la subjetividad del autor postulada por la estética romántica no se realiza en estos poemas, que defraudan así la expectativa de lectura (Charles-Wurtz, I998: 485). En «Les Djinns», el yo lírico es el protagonista 
de un drama nocturno, es «persona», personaje musulmán arrinconado por la amenazadora presencia de los djinns. Es posible que esa máscara, esa persona o rol ofreciera justamente el margen de libertad del que hicieron uso Avellaneda y Bello en sus respectivas imitaciones.

Desde el título y desde su primera estrofa «Les Djinns» localiza al hablante en un entorno oriental: una aldea (v. I) a orillas del mar (v. 5) en la noche (v. 8). A medida que avanza el poema, los djinns van acercándose, van cercando el espacio del hablante (v. 59: «ma demeure»/ mi morada); cercado por los djinns, el espacio del hablante lírico va reduciéndose, mientras paralelamente aumenta su pánico. La amenazadora presencia de estas criaturas nocturnas es percibida como un sonido cada vez más ensordecedor (v. Io: «bruit», v. 25: «rumeur»; v. 33: «voix sépulcrale»; v. 42: «tourbillonne en sifflant»), hasta llegar al paroxismo en la estrofa central, compuesta en versos alejandrinos (v. 57: «cris de l'enfer, voix qui hurle»). En ese momento de máximo peligro el yo, acorralado, pide protección al profeta (v. 65), invocado sin más atributos, contra los impuros demonios de la noche (v. 65s.). La plegaria surte efecto, y la bandada de djinns comienza a alejarse poco a poco, el ruido va decreciendo (v. 82: «le battement décrôit»; v. Ior: «leur essaim gronde»; v. I05: «Ce bruit vague») hasta desaparecer en el espacio, otra vez infinito, que extingue el rumor final (v. II8ss.). El momento central del poema lo constituye la invocación: la plegaria pone al hablante bajo el auspicio del profeta, a quien no ha llamado en vano.

Gertrudis Gómez de Avellaneda y Andrés Bello retoman esta situación de habla performativa, en la que el yo lírico asediado por las criaturas de la noche, pide ayuda a una instancia trascendente, y la obtiene. Sin embargo los cambios que introducen la escritora cubana y

el autor venezolano en sus respectivas versiones son decisivos.

En lo que sigue, analizaré a partir de esta pragmática algunas estrategias de traducción de Andrés Bello y de Gertrudis Gómez de Avellaneda, en particular en la versión definitiva de I869 de la escritora cubana, que es sin duda la más interesante de las imitaciones del poema de Víctor Hugo, y expondré finalmente algunas conclusiones de validez algo más general.

\section{LOS DUENDES DE ANDRÉS BELLO}

Bello acompaña la publicación de su «imitación de Víctor Hugo», como dice el subtítulo, con una nota del traductor al pie del texto publicado en El Progreso, de Santiago de Chile el ig de julio de 1843. La nota dice: «La idea general, algunos pensamientos y el progresivo ascenso y descenso del metro, es todo lo que se ha tomado del original. La composición francesa se titula Les Lutins» (Bello, I98ra: 229).

Podemos explicar como parte de una recontextualización y de una estrategia de aclimatación el hecho de que tanto Bello como Avellaneda opten por neutralizar desde el título la isotopía orientalista y traducir «Les Djinns» como «Los duendes», pero que Bello retraduzca en esta nota del traductor literalmente su propio título al francés alterando el título original del poema de Víctor Hugo, es un gesto, por lo menos, inusual. Volveré a este punto después de analizar algunas estrategias de aclimatación vinculadas con la pragmática de la versión de Bello, porque este análisis puede ofrecer alguna clave para explicar el cambio.

Llama la atención casi desde el comienzo, la ambientación americana y concretamente chilena del espacio en que tienen lugar tanto la acción como el acto de habla - tanto el poema de Víctor Hugo como ambas versiones utilizan 
verbos en presente, proponiendo una sincronía entre tiempo del enunciado y de la enunciación. Al escuchar el «ruido sordo» (v. 29s.) que anuncia la aproximación de los duendes, el yo se pregunta: «iEs el soplo / de los Andes / atizando / los volcanes?» (v. 39-42); compara luego el ruido amenazante y cercano con un «terremoto» (v. I22), y el rumor de los duendes alejándose con la «impetüosa corriente» (v. 212) de la «gigantesca cordillera» (v. 210) en épocas de deshielo. La isotopía del paisaje chileno es evidente, con mayor o menor énfasis a lo largo de los 3II versos. Se trata de una estrategia de traducción típica de Andrés Bello también en otras versiones de Víctor Hugo (Pagni, 2004).

Otra aclimatación fundamental tiene que ver con la religión: el hablante lírico no se dirige con su plegaria al "profeta», sino a distintas instancias del panteón católico y específicamente chileno: le reza a la «Virgen del Carmelo» (v. 95), que es la patrona de Chile, prometiendo llevarle flores y cirios (v. I05-I08), a «San Antón» (v. II9), a «jJesús!» (v. I25), y termina exclamando «iMisericordia, cielo!» (v. I6I), antes de que la plegaria surta efecto. Es evidente que a Bello le interesa recalcar la identidad católica de la divinidad a la que pide ayuda, mientras que en el caso de Víctor Hugo la invocación se limita a una sola palabra — «profeta»—, que define a la entidad invocada como islámica. Correlativamente, los duendes son calificados de «ángeles enemigos» (v. 98), «legión de Lucifer» (v. I48), «hueste infernal» (v. I67 y I78), «Satanás y su gente» (v. 193) etc., dándole al imaginario católico del infierno un lugar casi inexistente en el poema de Víctor Hugo, que sólo lo alude en el epígrafe del Inferno de Dante, que Bello sin embargo omite. En consonancia con la estrategia de aclimatación al catolicismo, si en «Les Djinns» la plegaria provoca inmediatamente el alejamiento de los espíritus malignos, en el poema de Bello es el tañido de la campana de «la iglesia vecina» el que espanta y aleja a las criaturas infernales.

No es necesario profundizar esta lectura, para comprobar que Bello vierte los elementos del imaginario orientalista francés al imaginario católico sudamericano y chileno, desplazando e incluso eliminando la isotopía orientalista.

Mencioné ya el discurso que Bello pronuncia con motivo de la instalación de la Universidad de Chile y de su asunción como rector en septiembre de 1843 . Hay que leer ese discurso como toma explícita de posición en la polémica literaria que había tenido lugar en Santiago de Chile en el año I842 en torno al romanticismo, a la libertad del arte, y a Víctor Hugo en particular (Durand, r96r: 98ss.). La polémica había sido iniciada por Vicente Fidel López en las páginas de la Revista de Valparaíso en mayo de I842, y Bello hasta el momento sólo había participado en ella indirectamente, a través de las posiciones mesuradas de su discípulo Salvador Sanfuentes, condenando entre otras libertades románticas las que se toma Víctor Hugo en el Ruy Blas.

En ese discurso, dos meses después de publicado «Los duendes», Bello compara, distinguiéndolas, «a la Europa y a nuestra afortunada América, con los sombríos imperios del Asia, en que el despotismo hace pesar su cetro de hierro sobre cuellos encorvados de antemano por la ignorancia». «¿Quién prendió en la Europa esclavizada las primeras centellas de libertad civil? [...] ¿ No fue la herencia intelectual de Grecia y Roma, reclamada, después de una larga época de oscuridad, por el espíritu humano?» (Bello, I98Ib: 6), pregunta retóricamente el novel rector tomando partido por el helenismo clásico dieciochesco e ilustrado contra el nuevo orientalismo romántico que ponen en escena los poemas de Víctor Hugo, y que el autor fran- 
cés defiende y proclama como nueva bandera en el prefacio de Les Orientales.

En ese mismo discurso, Bello toma partido 48 también contra quienes «[c]alumnian, no sé si diga a la religión o a las letras, los que imaginan que pueda haber una antipatía secreta entre aquéllas y éstas» (Bello, i98Ib: 6). Podría pensarse que en «Los duendes» Bello efectúa una operación transculturadora consecuente con las posiciones que defenderá poco después en su discurso, en la medida en que se trata de un poema acerca de la Victoria de la religión católica (como aliada de la literatura) sobre las tentaciones de lo informe, lo sombrío y lo caótico («batahola», «chusma turbulenta», «diabólico alboroto»).

Si volvemos ahora a la pregunta por los motivos que pudieron haber llevado a Bello a escribir en una nota de traductor que el poema de Víctor Hugo que él imita en «Los duendes» se titula «Les Lutins», podríamos concluir que se trata de un intento de borrar definitivamente la isotopía orientalista, en la que el título francés «Les Djinns» se inscribe explícitamente, legitimando una relectura del poema en clave católica, y apropiándose de la controvertida figura de Víctor Hugo en un sentido acorde con los parámetros que Bello defendía contra López y Sarmiento, que habían hecho justamente de Víctor Hugo su portavoz como representante de las nuevas tendencias poéticas europeas.

\section{LOS DUENDES DE GERTRUDIS GÓMEZ DE AVELLANEDA}

En las versiones poco divergentes entre sí de I84I y I850, Gertrudis Gómez de Avellaneda mantiene la invocación al profeta como punto de inflexión del movimiento del poema, y no aclimata el espacio al modo de Bello, pero al final efectúa un agregado que será importante para entender la génesis de la versión de I869, cuyas transformaciones respecto de las versiones previas son decisivas. Donde la actitud del yo lírico de Víctor Hugo hacia el final del poema consiste en escuchar el silencio del espacio nocturno y cederle, por así decir, la palabra -los últimos versos dicen «L'espace / efface / le bruit» (el espacio / extingue / el ruido)en el poema de Avellaneda los últimos versos remiten al yo: "Y en sosiego / Tan profundo / Duerme el mundo / ¡Y yo también!».

Si comparamos ahora la versión de I869 con las anteriores y la cotejamos con el poema de Víctor Hugo, llama la atención en primer lugar que el yo lírico sea ahora explícitamente femenino; ya en la primera parte del poema es una mujer la que habla: «Son ¡oh cielo! Son los duendes, / Que - enemigos de mi paz- / Cada noche, en turba inmensa, / Visitan mi soledad. // Son los duendes, que mi insomnio / Parece siempre evocar, / Para burlarme, auturdirme, / Volverme loca quizás.» (subrayado mío). Si en el poema de Víctor Hugo - y también en la versión de Bello- los duenden provocan el insomnio, ahora es el insomnio - un tema predilecto de Avellaneda- el que convoca a los duendes, que llegan para enloquecer a la mujer despierta en medio de la noche.

Después de este cambio fundamental, Avellaneda retoma el texto de la versión previa con muy pocas, pero decisivas transformaciones. La más importante es la invocación. En las versiones de I84I y I850 el texto decía: «¡Profeta! Si tu mano / Me puede libertar / Prosternaré mi frente / Delante de tu altar». Avellaneda había optado inicialmente por darle al hablante el rol de creyente musulmán que tiene en el poema de Víctor Hugo. En I869 la invocación dice: « $¡ \mathrm{Oh}$ Musa! Si tu mano / Me ofrece libertad, / Prosternaré mi frente / Delante de tu altar». Ahora la hablante, que ya se ha revelado como mujer, 
se define como mujer que escribe y que invoca a la musa inspiradora, para salvarse, escribiendo, de la locura que la amenaza en sus noches insomnes.

Otros cambios de la versión de 1869 van en el mismo sentido de darle mayor peso a la figura y la experiencia de la hablante: «iEl techo retiembla / sobre mi agitado!», en lugar de: «iEl techo retiembla, / Suena de contino!»; «Mas en los aires cadenas / Aun me parecen crujir», en lugar de la forma impersonal: «Y en el aire las cadenas / Se oyen chocar y crujir». O bien: «Mis enemigos veloces» en lugar de la forma previa: «Huyen los duendes veloces» (en todos los casos los subrayados son míos). El final del poema coincide literalmente con el de las primeras versiones, pero ahora se lee de otro modo: «Todo cesa... / Ningún ruido / A mi oído / Llega ya; / Todo calla, / Y el reposo / Silencioso / Tornará. / Ya benigno / Vierte el sueño / Su beleño / Por mi sien. / Y en sosiego / Tan profundo / Duerme el mundo... / ¡Y yo también!». La tercera versión de «Los duendes» es un poema sobre la escritura femenina y la locura. Más aún: escribiendo el poema la hablante consigue ahuyentar a los duendes del insomnio, consigue evitar la locura.

Podemos conjeturar que el hecho de que se trate aquí, explícitamente de una «imitación de Víctor Hugo» le permitió a Avellaneda articular una poética femenina ocultándose tras la máscara del poeta francés; como sostiene Susan Kirkpatrick, con sus imitaciones de los poetas franceses e ingleses consagrados de su tiempo - Lamartine, Byron, Hugo - la escritora cubana buscaba legitimar su poesía (Kirkpatrick, I99I: I69). Al imitar una voz masculina consagrada, Gertrudis Gómez de Avellaneda delega la originalidad y se pone al resguardo de la crítica masculina que le exige que escriba, como mujer que es, con «aquella suavidad y ternura que parecía debía ser el carácter distintivo del bello sexo» (Kirkpatrick, I99I: I66).

\section{CONCLUSIONES}

Andrés Bello y Gertrudis Gómez de Avellaneda leen cada uno a su modo "Les Djinns»: Bello lo lee en clave chilena y católica, se apropia del texto de Víctor Hugo, lo aclimata y elimina -incluso alterando el título del poema francés- la isotopía orientalista, convirtiendo su traducción en un alegato en favor del vínculo estrecho entre religión católica y literatura como punto de partida de una poesía chilena e hispanoamericana que conjugue la libertad romántica que Víctor Hugo simboliza - y que se evidencia aquí, por ejemplo, en el experimento métrico- y la norma moral que Bello considera inapelable. Los duendes son en su poema las tentaciones del demonio a las que el yo controla con ayuda de la religión; el poema es el espacio en el que adquiere su expresión esa victoria de las fuerzas del orden contra el caos.

Gertrudis Gómez de Avellaneda lee «Les Djinns», en cambio, en clave de género. También ella se apropia del poema de Víctor Hugo, pero para inscribir en él la subjetividad femenina, eliminando tanto la identidad marcadamente ficticia del yo, la distancia explícita entre sujeto del enunciado y de la enunciación, como así también la marca orientalista.

En ambas versiones analizadas el Oriente desaparece. En el caso de Bello, porque en su concepción de América la filiación europea que él subraya implica rechazar justamente la analogía orientalista que sin embargo utilizará exitosamente Sarmiento (Altamirano, I994); Bello se apropia de Víctor Hugo, uno de los autores predilectos de Sarmiento, para esgrimirlo contra Sarmiento y los defensores de la libertad absoluta en la literatura dentro del 
incipiente campo cultural chileno. En cuanto a Avellaneda, podemos conjeturar que la isotopía orientalista desaparece porque las fuerzas del caos que la hablante por fin derrota con ayuda de la musa, no constituyen una alteridad externa; el conflicto es interior y se dirime en el acto mismo de la creación poética por parte de la hablante-poeta-mujer.

En ambos casos la traducción, que tanto Gertrudis Gómez de Avellaneda como Andrés Bello prefieren denominar «imitación», en el sentido de una recreación consciente, no tiene por finalidad importar el poema de Víctor Hugo al contexto de la poesía chilena, española o hispanocubana de mediados del siglo XIX como un producto externo enriquecedor, sino incorporarlo como materia prima al proceso de producción de una literatura propia. Es un gesto frecuente, por lo demás, en el marco de la construcción de las nuevas literaturas nacionales hispanoamericanas -en el caso de Andrés Bello- o de la construcción de un lugar de enunciación para la mujer que escribe - en el caso de Gertrudis Gómez de Avellaneda-.

RECIBIDO EN ENERO 2008 ACEPTADO EN FEBRERO 2008

\section{BIBLIOGRAFÍA}

Altamirano, C. (I994). «El orientalismo y la idea del despotismo en el Facundo». L. Area y M. Moraña (eds.). La imaginación histórica en el siglo XIX. Rosario: UNR Editora, pp. 265-276.

Bello, A. (r98ra). "Los duendes». Obras Completas de Andrés Bello I: Poesias. Caracas: La Casa de Andrés Bello, pp. 229-237.

Bello, A. (I98Ib). «Discurso pronunciado en la instalación de la Universidad de Chile el día i7 de setiembre de 1843". Obras Completas de Andrés Bello XXI: Temas educacionales I. Caracas: La Casa de Andrés Bello, pp. 3-2I.

Durand, R. L.F. (I96I). La poésie d'Andrés Bello. Dakar: Publications de la Section de Langues et Littératures de la Faculté de Lettres.

Charles-Wurtz, L. (1998). Poétique du sujet lyrique dans l'oeuvre de Victor Hugo. Paris: Champion.

Gómez de Avellaneda, G. (I84I). Poesías. Madrid: Prensa Tipográfica.

Gómez de Avellaneda, G. (I850). Poesías. Madrid: Delgras Hermanos.

Gómez de Avellaneda, G. (1974). Obras. Ed. J. M. Castro y Calvo. Biblioteca de Autores Españoles 278. Madrid: Atlas [reproduce Poesías. I869].

Hugo, V. (1996). Les Orientales. Les Feuilles d'automne. Édition établie par P. Albouy. Paris: Gallimard.

Kirkpatrick, S. (I99I). Las Románticas. Escritoras y subjetividad en España, I835-1850. Madrid: Ediciones Cátedra.

Pagni, A. (2004). «Olimpio en América: Usos hispanoamericanos del romanticismo francés». A. Pagni (ed.): América Latina: Espacio de traducciones. Estudios. Revista de Investigaciones Literarias y Culturales 24, pp. II7-I32.

Venuti, L. (1998). The Scandals of Translation. Towards an Ethics of Difference. Manchester: St. Jerome Publishing. 